\title{
Aeroelastic studies of a cable stayed bridge in Talavera de la Reina, Spain
}

\author{
S. Hernández, F. Nieto \& J. Á. Jurado \\ School of Civil Engineering, University of Coruña, Spain
}

\begin{abstract}
The cable stayed bridge of Talavera de la Reina in central Spain is a signature structure of a high aesthetic quality, the main span is $318 \mathrm{~m}$ long and the single pylon reaches $164 \mathrm{~m}$ of height. Due to the relevance of the bridge a study of the wind characteristics at the location and a set of aerodynamic studies both experimental and computational were carried out to anticipate the future response of the bridge under wind flow. They comprised a boundary layer wind tunnel test of the stand alone pylon and the full bridge, a test of a reduced model of a segment of the deck in an aerodynamics wind tunnel and computational analysis to obtain the flutter speed of the bridge. This paper describes the bridge and the results of the mentioned studies that allowed us to conclude that the bridge could perform safely while subjected to the expected wind speed at its location.

Keywords: cable stayed bridges, boundary layer wind tunnel, aeroelastic studies, flutter speed.

\section{The Talavera de la Reina bridge}

This cable stayed bridge is located south of the Talavera de la Reina city in central Spain; the purpose of the construction is to provide a crossing over the Tagus river. The structure is a quite singular design with a concrete deck of aerodynamic shape, a main span of $318 \mathrm{~m}$ and a single pylon $164 \mathrm{~m}$ tall. The cable system is 3-D with the deck supported by two planes of cables and another pair of families of rear cables balancing the pylon and anchored in massive concrete blocks. Figure 1 shows some details of the bridge.
\end{abstract}




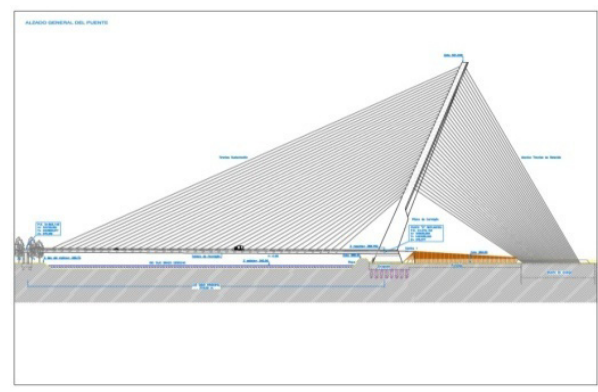

a) Elevation

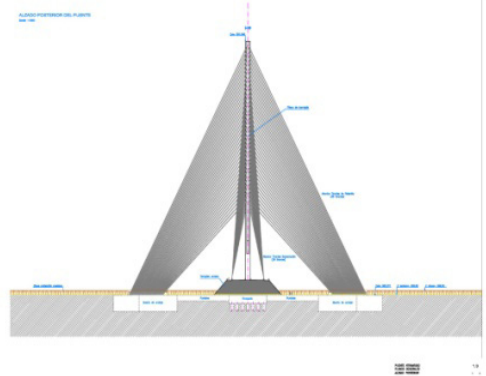

b) Rear view

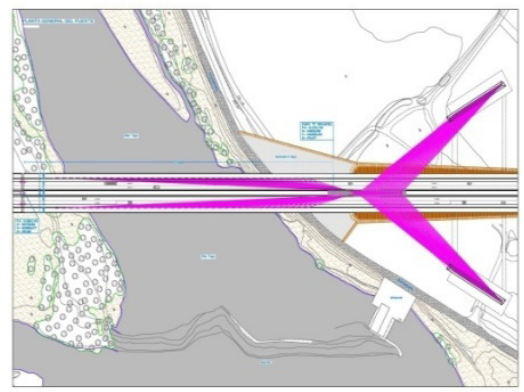

c) Plan view

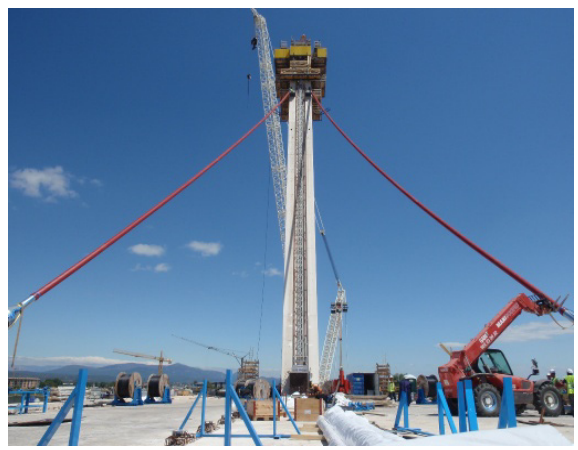

e) Pylon view

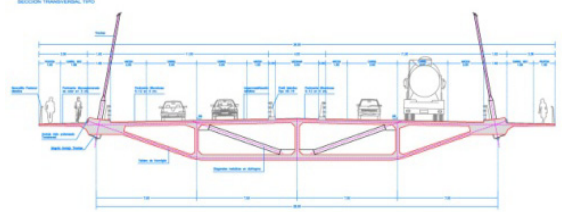

d) Bridge deck

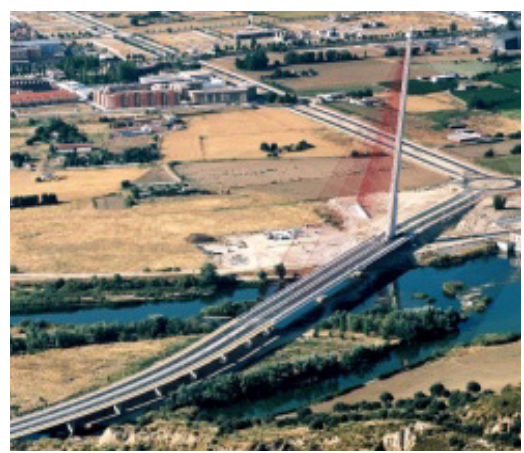

f) Full bridge view

Figure 1: Geometry of the cable stayed Talavera bridge.

\section{Aerodynamic studies}

Taking in account the relevance of the bridge several studies related to the influence of the wind in the structural behaviour were carried out they are listed below

a) Wind characteristics at bridge site.

b) Test of stand alone pylon. 
c) Aerodynamic coefficients of bridge deck.

d) Evaluation of flutter speed of bridge.

\section{Wind characteristics at bridge site}

A study of wind properties at bridge site was very necessary [1]. It had to provide the maximum speed values expected for the return period required. The vertical profile of wind velocity was also relevant as the tall pylon was to stand alone during several months during the construction works. Additionally the identification of the wind rose was very useful to find out the wind flow orientations that were move probe to occur.

Daily data of wind speed data came from a weather station nearby of bridge location and they were recorded at a high of $10 \mathrm{~m}$. A threshold value of $30 \mathrm{~km} / \mathrm{h}$ was defined and only events of higher speed were considered in the study. Hence, up to 101 data in a time period of 11 years were considered and they appear in table 1.

Table 1: $\quad$ Vertical wind profile for different return periods.

\begin{tabular}{|c|c|c|c|c|c|}
\hline \multicolumn{2}{|c|}{$T=200$ years } & \multicolumn{2}{|c|}{$T=50$ years } & \multicolumn{2}{|c|}{$T=5$ years } \\
\hline$z(m)$ & $U(\mathrm{~km} / \mathrm{h})$ & $z(m)$ & $U(\mathrm{~km} / \mathrm{h})$ & $z(m)$ & $U(\mathrm{~km} / \mathrm{h})$ \\
\hline 0 & 0.00 & 0 & 0.00 & & 0.00 \\
\hline 5 & 108.73 & 5 & $\begin{array}{l}96.87 \\
\end{array}$ & & 77.12 \\
\hline 10 & 122.88 & 10 & 109.49 & & 87.16 \\
\hline 15 & 131.18 & 15 & 116.88 & & 93.04 \\
\hline 20 & 137.07 & 20 & 122.13 & & 97.22 \\
\hline 25 & 141.64 & 25 & 126.20 & & 100.46 \\
\hline 30 & 145.37 & 30 & 129.53 & 3 & 103.11 \\
\hline 35 & 148.53 & 35 & 132.34 & 3 & 105.35 \\
\hline 40 & 151.27 & 40 & 134.78 & 4 & 107.29 \\
\hline 45 & 153.68 & 45 & 136.93 & 4 & 109.00 \\
\hline 50 & 155.84 & 50 & 138.85 & & 110.53 \\
\hline 55 & 157.79 & 55 & 140.59 & 5 & 111.92 \\
\hline 60 & 159.58 & 60 & 142.18 & 6 & 113.18 \\
\hline 65 & 161.22 & 65 & 143.64 & 6 & 114.35 \\
\hline 70 & 162.73 & 70 & 145.00 & & 115.42 \\
\hline 75 & 164.15 & 75 & 146.26 & & 116.43 \\
\hline 80 & 165.47 & 80 & 147.43 & & 117.37 \\
\hline 85 & 166.71 & 85 & 148.54 & & 118.25 \\
\hline 90 & 167.89 & 90 & 149.59 & 9 & 119.08 \\
\hline 95 & 168.99 & 95 & 150.57 & 9 & 119.86 \\
\hline 100 & 170.05 & 100 & 151.51 & 10 & 120.61 \\
\hline 105 & 171.05 & 105 & 152.40 & 10 & 121.32 \\
\hline 110 & 172.00 & 110 & 153.25 & 11 & 121.99 \\
\hline 115 & 172.91 & 115 & 154.06 & 11 & 122.64 \\
\hline 120 & 173.78 & 120 & 154.84 & 12 & 123.26 \\
\hline 125 & 174.62 & 125 & 155.59 & 12 & 123.85 \\
\hline 130 & 175.42 & 130 & 156.30 & 13 & 124.42 \\
\hline 135 & 176.20 & 135 & 156.99 & 13 & 124.97 \\
\hline 140 & 176.94 & 140 & 157.65 & 14 & 125.50 \\
\hline 145 & 177.66 & 145 & 158.30 & 14 & 126.01 \\
\hline 150 & 178.36 & 150 & 158.91 & 15 & 126.50 \\
\hline 155 & 179.03 & 155 & 159.51 & 15 & 126.98 \\
\hline 160 & 179.68 & 160 & 160.09 & 16 & 127.44 \\
\hline 165 & 180.31 & 165 & 160.66 & 16 & 127.89 \\
\hline 170 & 180.92 & 170 & 161.20 & 17 & 128.32 \\
\hline 175 & 181.52 & 175 & 161.73 & 17 & 128.75 \\
\hline 180 & 182.09 & 180 & 162.24 & 18 & 129.15 \\
\hline 185 & 182.65 & 185 & 162.75 & 18 & 129.55 \\
\hline 190 & 183.20 & 190 & 163.23 & 19 & 129.94 \\
\hline 195 & 183.73 & 195 & 163.71 & 19 & 130.32 \\
\hline 200 & 184.25 & 200 & $\begin{array}{l}164.17 \\
\end{array}$ & 20 & 130.69 \\
\hline
\end{tabular}


Wind speed $U$ at the reference altitude from the ground of $10 \mathrm{~m}$ was fitted to a Gumbel distribution defined as

$$
F(U)=e^{\frac{-U-a}{b}}
$$

Data fitting was obtained with a value of correlation coefficient of $R^{2}=0.99$ Parameters $a, b$. turn out

$$
a=50.292 \quad b=0.653
$$

Having obtained the parameters of the expression of $F(U)$ in (1) the wind speed $U_{T}$ corresponding to a return period $T$ can be written as

$$
U_{T}=a-b \ln \left(-\ln \left(1-\frac{n}{N T}\right)\right.
$$

where $n=11$ is the number of the years included in the study, $N$ the number of events and $T$ the years of the return period.

Vertical profile of wind was defined by the expression

$$
U(z)=\frac{U^{*}}{k} \ln \frac{z}{z_{0}}
$$

where $k=0.4$ is the well known Von Karman constants, $z_{0}$ is roughness length for which a value of $z_{0}=0.025 \mathrm{~m}$ was selected according with the topographical conditions.

The values of $U(z)$ at $z^{*}=10 \mathrm{~m}$ for any return period $T$ are obtained in expression (3). Therefore the value of $U_{T}^{*}$ can be identified easily as

$$
U_{T}^{*}=\frac{k U_{T}\left(z^{*}\right)}{\ln \frac{z^{*}}{z_{0}}}
$$

Entering with $U_{T}^{*}$ in expression (4) the vertical profile of wind speed for each return period $T$ can be evaluated. In table 2 values for several cases are shown.

Table 2: $\quad$ RMS of accelerations at pylon top.

\begin{tabular}{|l|l|l|}
\hline & $\begin{array}{l}\text { Return period } \\
T=5 \text { years }\end{array}$ & $\begin{array}{l}\text { Return period } \\
T=500 \text { years }\end{array}$ \\
\hline Stage 1 & $0.46 \mathrm{~m} / \mathrm{s}^{2}$ & $1 \mathrm{~m} / \mathrm{s}^{2}$ \\
\hline Stage 2 & $0.338 \mathrm{~m} / \mathrm{s}^{2}$ & $0.975 \mathrm{~m} / \mathrm{s}^{2}$ \\
\hline
\end{tabular}

The monthly wind rose describing the angular distribution of wind flow appears in figure 2. Yearly wind rose and bridge position are in figure 3 and it shows that the most frequent wind orientation is almost perpendicular to the bridge. 


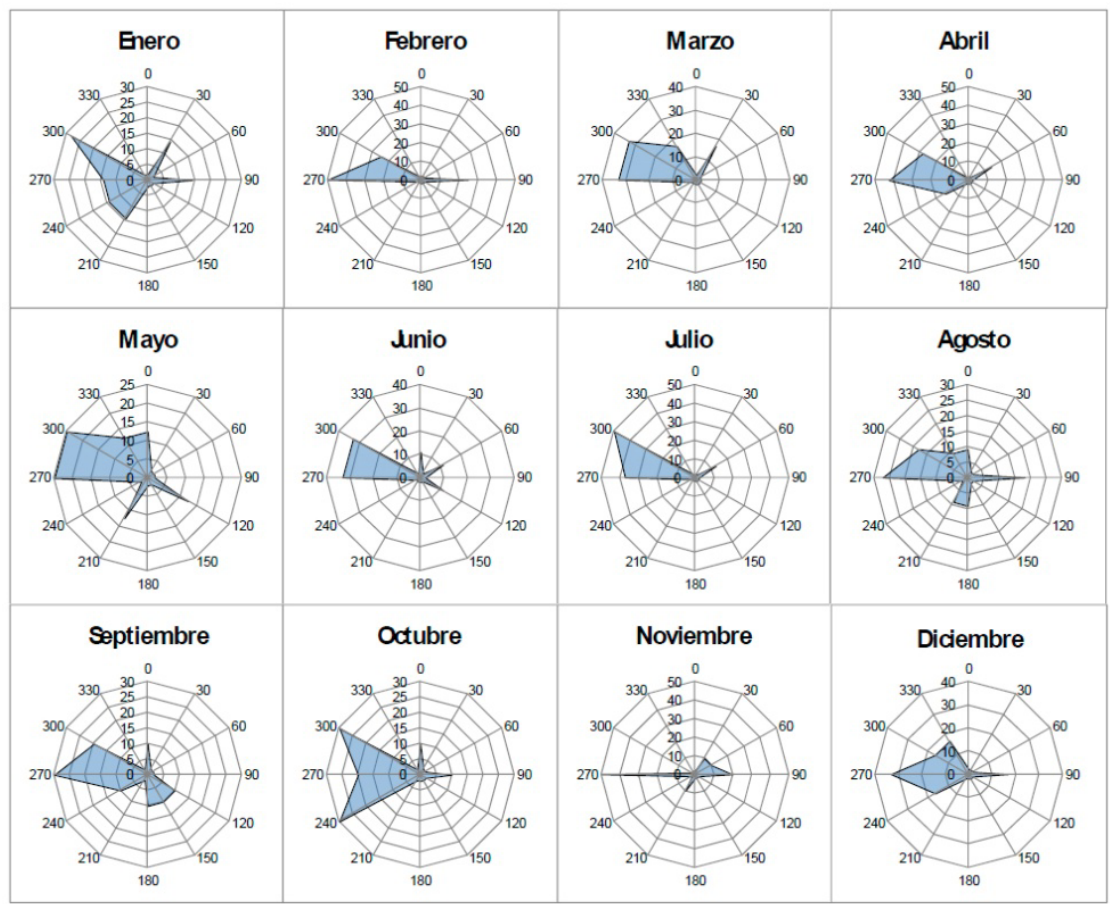

Figure 2: $\quad$ Monthly wind rose.

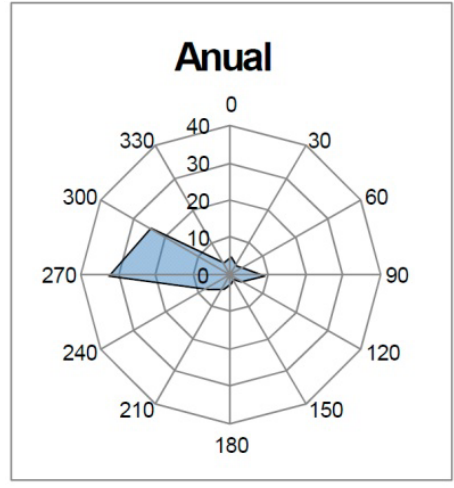

a) Yearly wind rose

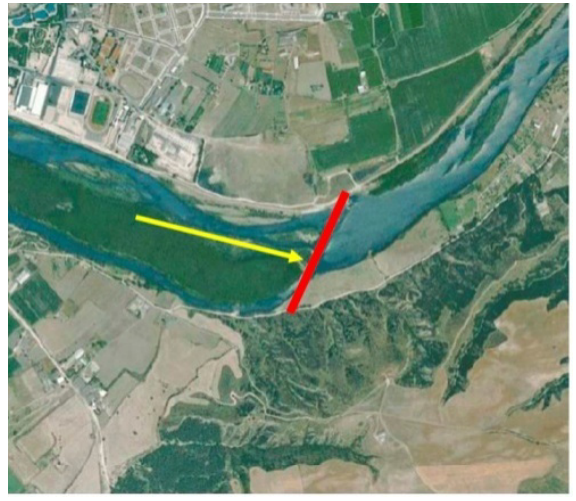

b) Bridge location

Figure 3: $\quad$ Yearly wind rose and bridge location.

\section{Test of stand alone pylon}

The construction procedure of the cable stayed bridge contained phases in which the pylon is partially built up to a height of $71.44 \mathrm{~m}$ and is not connected to any 
cable, thus it behaves as a vertical cantilever under wind flow. Afterwards, as the pylon construction progresses some cables are placed in the pylon and connected to the bridge deck, so the pylon stiffness is increased. A study of the erection steps of the pylon showed that the two critical situations where when it reached the maximum cantilever height and also the next phase when, after building a new pylon module, and therefore its height mounted up to $79.46 \mathrm{~m}$ the pylon was connected with two cables to bridge deck. Both situations are presented in figure 4 .

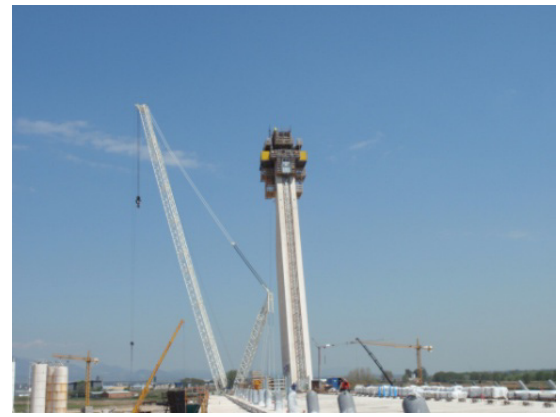

a) Maximum cantilever height

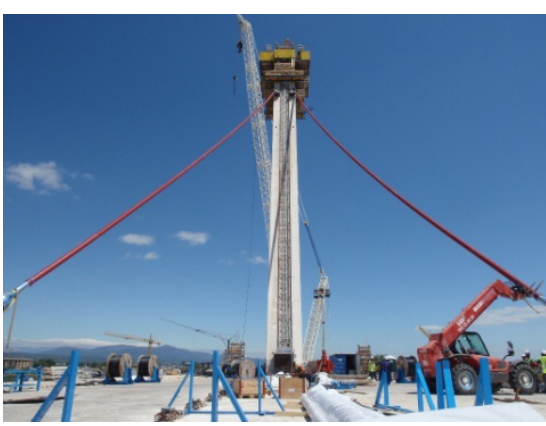

b) Pylon connected with two cables

Figure 4: Critical phases of pylon construction.

Considering this information a test of the pylon was carried out in the boundary layer wind tunnel of the Politecnico de Milano [2] using a reduced model with a geometrical scale of $1 / 64$. Figure $5 a$ ) shows a detail of the reduced

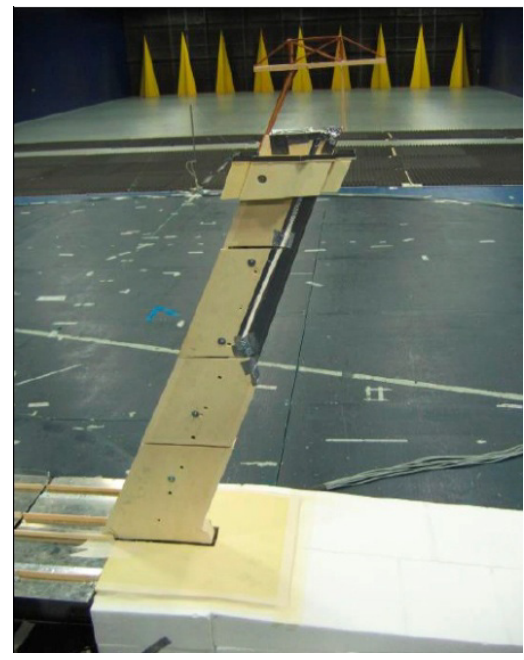

a) Pylon with formwork and crane

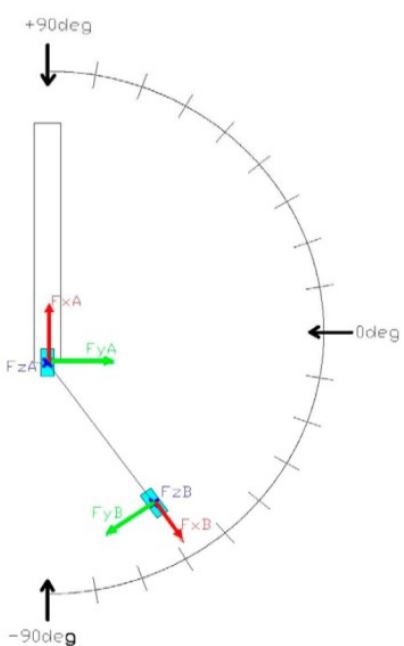

b) Convention signs in experiment

Figure 5: $\quad$ Test of the pylon in the wind tunnel. 
model of the pylon that incorporates details of the equipment existing at the top; also the convention sign adopted in the experiment is shown in figure 5b).

The reduced model was tested in two configurations entitled Stage 1 (stand alone pylon of $71.44 \mathrm{~m}$ ) and Stage 2 (pylon of $79.46 \mathrm{~m}$ connected with two cables). Wind speeds in the experiment corresponded to those of 5 years and 500 years return period for actual wind. The pylon exhibited vibrations under both flows being larger when wind was in $x$ direction and vibrations occurred in the perpendicular axis, namely on $y$ directions according to the sign convention.

The RMS of accelerations at pylon top appears in table 3.

Table 3: $\quad$ Data of reduced model and springs.

\begin{tabular}{|c|c|c|c|c|c|}
\hline & \multicolumn{3}{|c|}{$\begin{array}{l}\text { SECTIONAL MODEL MASS } \\
\text { SECTIONAL MODEL INERTIA } \\
\text { MODEL WIDTH } \\
\text { DISTANCE d }\end{array}$} & $\begin{array}{l}3.2 \mathrm{~kg} \\
5.1 \mathrm{kgm}^{\wedge} 2 \\
0.36 \mathrm{~m} \\
0.47 \mathrm{~m}\end{array}$ & \\
\hline & VERTIC & PRINGS & HORIZONTAL & MODEL FRE & IUENCIES $(\mathrm{rad} / \mathrm{s})$ \\
\hline & TOP & ВОТТОМ & SPRING & \begin{tabular}{|l} 
LATERAL \\
\end{tabular} & VERTICAL TORSIONAL \\
\hline & $130 \mathrm{~N} / \mathrm{m}$ & $96 \mathrm{~N} / \mathrm{m}$ & $102 \mathrm{~N} / \mathrm{m}$ & 13.6 & $\begin{array}{ll}16.6 & 35.7 \\
\end{array}$ \\
\hline TEST 2 & $600 \mathrm{~N} / \mathrm{m}$ & & $300 \mathrm{~N} / \mathrm{m}$ & 21.1 & 26.1 \\
\hline
\end{tabular}

No proper regulation exists to define the allowable upper value of this type of accelerations but it is quite common to accept a maximum value of $0.5 \mathrm{~m} / \mathrm{s}^{2}$. In that regards it looks that the pylon is safe for both construction stages for the five years return period wind and it is not for the $\mathrm{T}=500$ wind speed. The test showed that the critical situation is when the pylon is at its maximum stand alone height.

It may be reminded that the values of accelerations in table 3 corresponded to wind in direction $x$ and the wind rose presented in figure 3.a indicates that this is not the most frequent wind direction. Additionally, the idea of checking the behaviour of the isolated pylon under a wind speed of return period $\mathrm{T}=500$ years looks too much protective taken in account that the pylon construction only lasts a few months. It seems that a return period of $\mathrm{T}=5$ years is more sensible.

\section{Evaluation of flutter speed of bridge}

Evaluation of bridge behaviour under laminar flow and the wind speed leading to instability was carried out by two different procedures.

\subsection{Evaluation by a hybrid method}

In this approach flutter speed was identified by a method consisting in a two step procedure. In the first one a reduced model a segment of bridge deck was tested in the wind tunnel of the University of Coruña. The geometric scale of the model was $1 / 100$ with a span to width ratio of 3 and the Reynolds number of the experiment was $\operatorname{Re}=2.16 \mathrm{E}+0.5$. Figure 6 shows a view of the wind tunnel with the test chamber in the forefront and a picture of the reduced model.

The aim of the text was to obtain the complete set of flutter derivatives defined by the Scalan formulation. The reduced model was placed in the test 


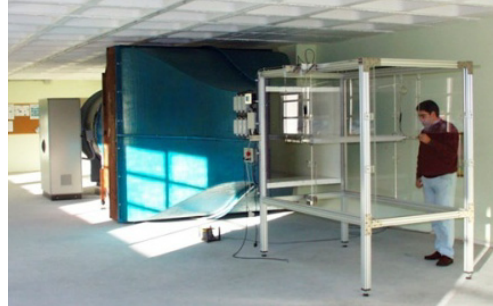

a) View of the wind tunnel

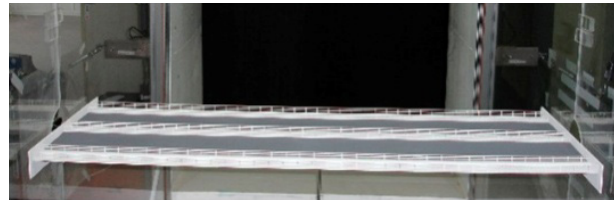

b) View of the reduced model of bridge deck

Figure 6: Wind tunnel test of a segment bridge deck.

chamber hanging on several springs as described in figure 7. Two different set of springs were used in order to allow a wider interval of wind velocities that ranged from $6 \mathrm{~m} / \mathrm{s}$ to $15 \mathrm{~m} / \mathrm{s}$. Data of reduced model and springs appear in table 4.
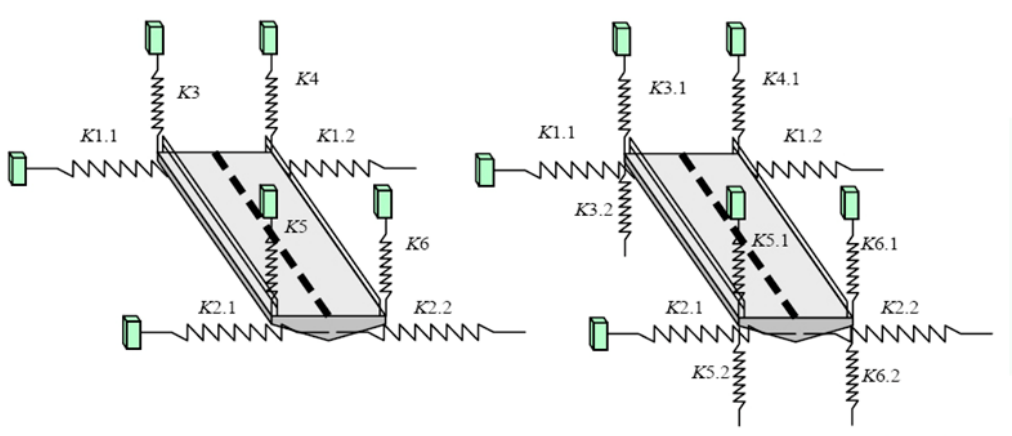

Figure 7: $\quad$ Suspension system of reduced model deck.

Figures 8 to 10 show the results of the $A_{i}^{*}, H_{i}^{*}, P_{i}^{*}(i=1, \ldots 6)$ flutter derivatives.

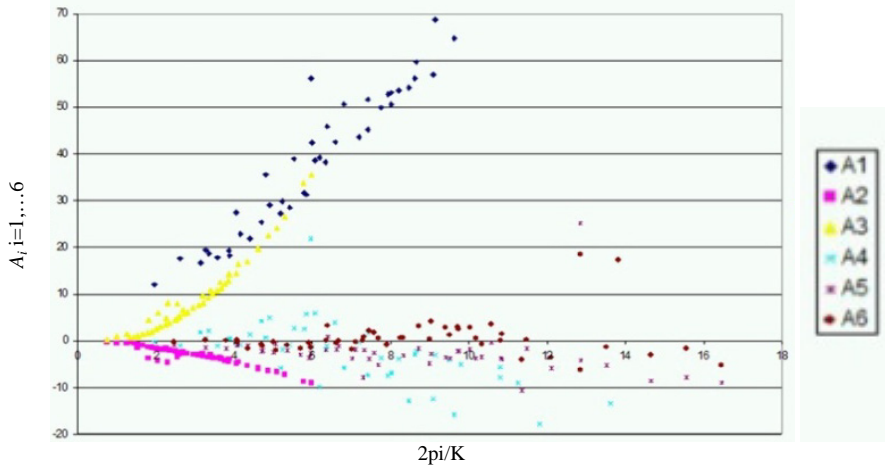

Figure 8: $\quad$ Values of $A_{i}^{*}(i=1, \ldots 6)$. 


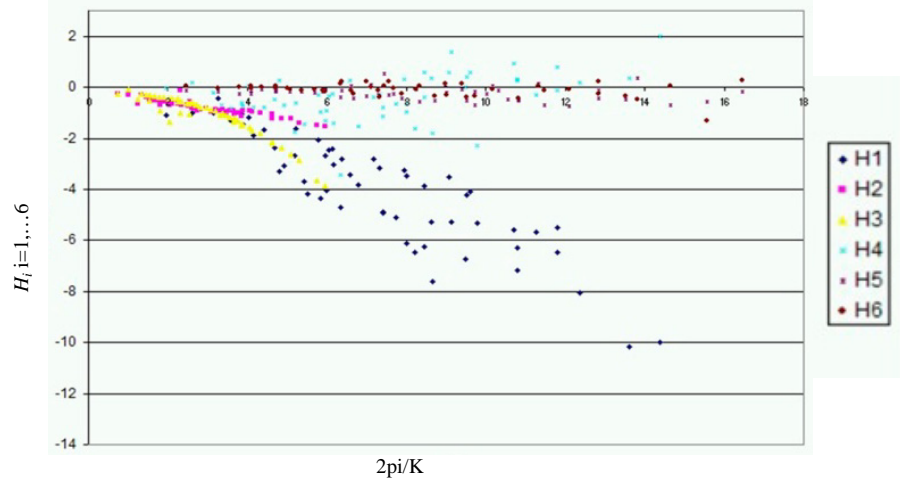

Figure 9: $\quad$ Values of $H_{i}^{*} \quad(i=1, \ldots 6)$.

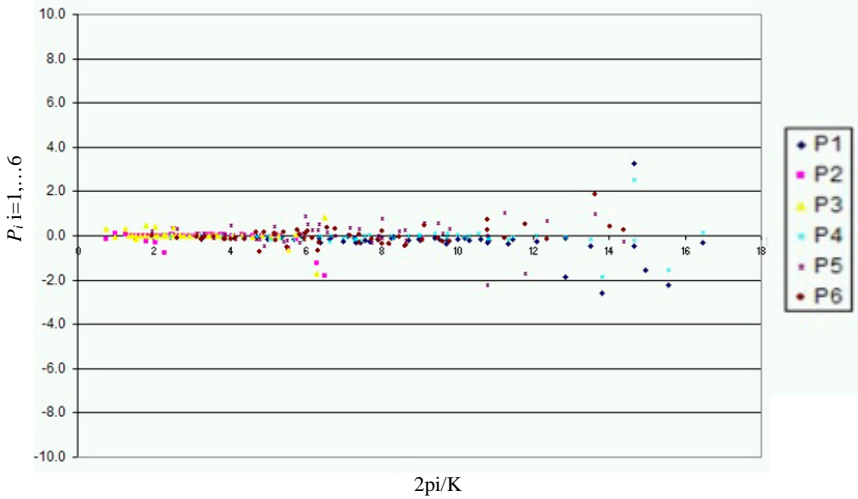

Figure 10: $\quad$ Values of $P_{i}^{*} \quad(i=1, \ldots 6)$.

The set of flutter derivatives allows us to formulate the aeroelastic forces according to expression (6).

$\mathbf{f}_{a}=\left\{\begin{array}{c}D_{a} \\ L_{a} \\ M_{a}\end{array}\right\}=\frac{1}{2} \rho U^{2} K B \cdot\left(\begin{array}{ccc}P_{1}^{*} & -P_{5}^{*} & -B P_{2}^{*} \\ -H_{5}^{*} & H_{1}^{*} & B H_{2}^{*} \\ -B A_{5}^{*} & B A_{1}^{*} & B^{2} A_{2}^{*}\end{array}\right)\left\{\begin{array}{c}\dot{v} \\ \dot{w} \\ \dot{\varphi}_{x}\end{array}\right\}+\frac{1}{2} \rho U^{2} K^{2} \cdot\left(\begin{array}{ccc}P_{4}^{*} & -P_{6}^{*} & -B P_{3}^{*} \\ -H_{6}^{*} & H_{4}^{*} & B H_{3}^{*} \\ -B A_{6}^{*} & B A_{4}^{*} & B^{2} A_{3}^{*}\end{array}\right)\left\{\begin{array}{c}v \\ w \\ \varphi_{x}\end{array}\right\}$

where $v, w, \varphi_{x}$ and $\dot{v}, \dot{w}, \dot{\varphi}_{x}$ are deck displacement and velocities according to the convention showed in figure $11, U$ is wind speed, $\omega$ is the vibration frequency, $k$ is the reduced frequency $k=\omega B / U$ and $A_{i}^{*}, H_{i}^{*}, P_{i}^{*} \quad(i=1, \ldots 6)$ are the flutter derivatives. 


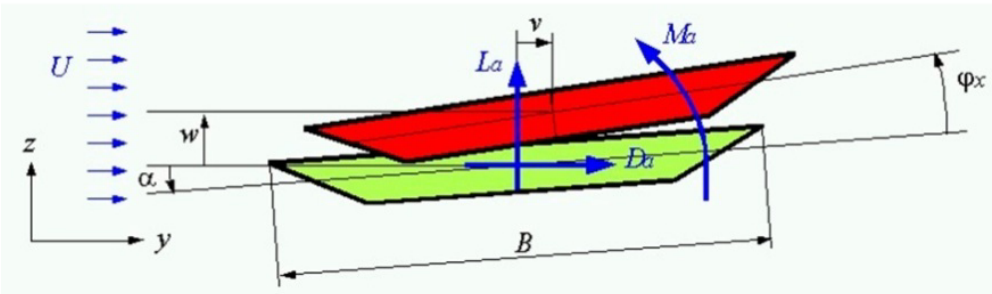

Figure 11: Convention signs for wind tunnel test.

After obtaining the flutter derivatives the dynamic equilibrium of the full bridge under wind flow can be expressed as

$$
\mathbf{M} \ddot{\mathbf{u}}+\mathbf{C} \dot{\mathbf{u}}+\mathbf{K u}=\mathbf{f}_{a}=\mathbf{C}_{a} \dot{\mathbf{u}}+\mathbf{K}_{a} \mathbf{u}
$$

Using modal superposition equation (7) leads to a non linear problem that needs to be solved for each wind speed $U$. It is well known that the solution consists on a set of complex eigenvalues whose real and imaginary components represent the damping and frequency of each eigenvector. When a damping becomes zero for a given wind speed the flutter speed is obtained.

Using the in-home code, FLAS [3] a flutter speed of $77.17 \mathrm{~m} / \mathrm{s}$ was find out. This is a very high velocity that means that the bridge is very stable aeroelastically.

\subsection{Test of full bridge under laminar flow}

A reduced model of the full bridge at a geometric scale 1/64 was tested in the boundary layer wind tunnel of the Politecnico di Milano [2].

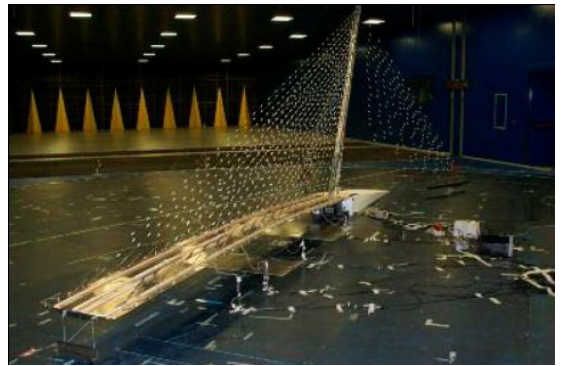

a) View of the reduced model

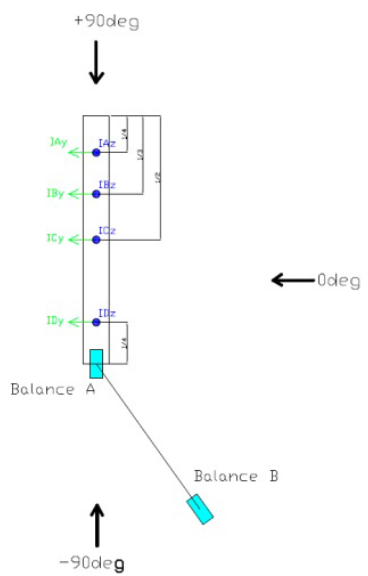

b) Location of the accelerometers

Figure 12: Picture of the model and locations of the measurement devices. 
The aim of the test in laminar flow was to investigate the damping effect as it usually increases for small wind speed and then this tendency changes for higher wind velocities and eventually it can become zero leading to incipient flutter.

Initial test showed a value of structural damping of $0.85 \%$ for the first eigenvector that was a flexural mode as it appears in figure 13.

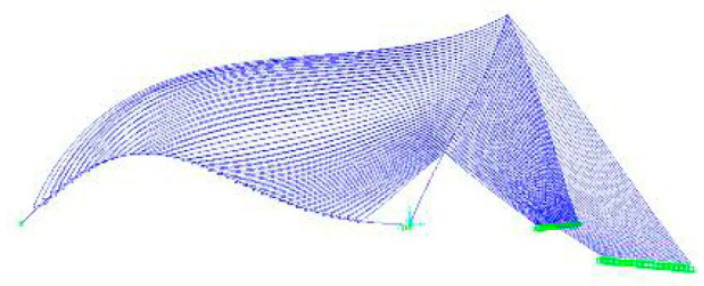

Figure 13: $\quad$ First flexural model of bridge.

Deformation of bridge under different wind speed and orientation was measured at positions $\mathrm{A}$ and $\mathrm{B}$ that are closer to the point of maximum deformation for the first flexural mode. Figure 14 and 15 shows the values of total damping (structural play aerodynamic) for increasing wind speed up to $7 \mathrm{~m} / \mathrm{s}$. It must be borne in mind that given the geometrical scale of $1 / 64$ that speed represents a real wind velocity of $56 \mathrm{~m} / \mathrm{s}$ or $201.6 \mathrm{~km} / \mathrm{h}$. It can be observed that for that range of wind speed total damping increases and there is no danger of instability. This result is consistent with the conclusion obtained in the computational calculations and therefore it can be said that the design of the bridge was very safe regarding flutter.

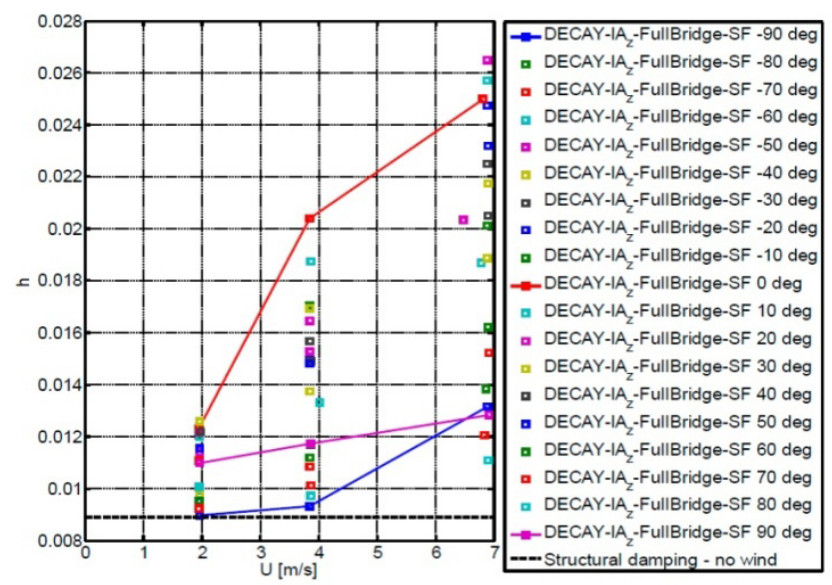

Figure 14: Total damping at location A. 


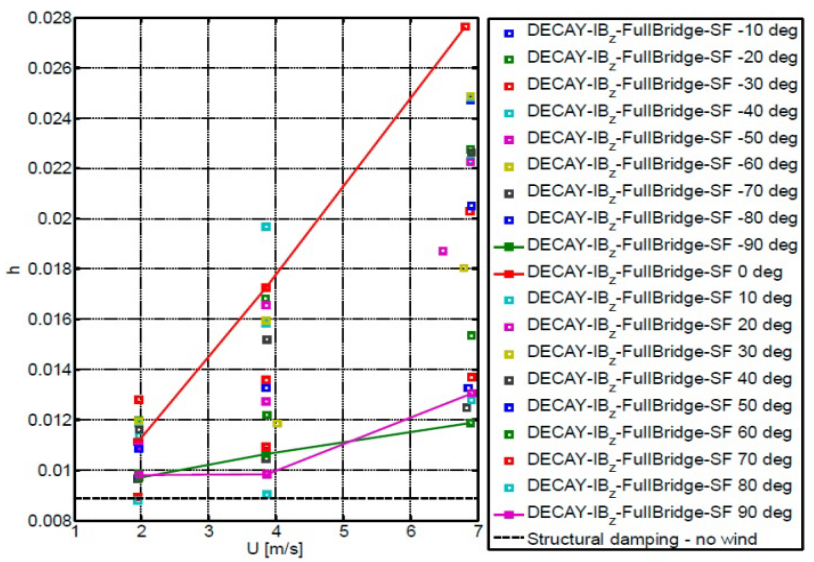

Figure 15: Total damping at location B.

\section{References}

[1] Hernández, S., Nieto, F., Jurado, J.Á., Pereira, F. and Díaz, A. Estudio experimental del puente atirantado de Talavera de la Reina en túneles de viento. University of La Coruña, 2008.

[2] Collina, A., Belloli, M., Posa, L., Squicciarini, G. Talavera cable stayed Bridge wind Tunnel Test. Politecnico di Milano, 2008.

[3] Jurado, J.Á., León, A., Nieto, F and Hernández, S. Flas-B: Software for the Hybrid Analysis of Flutter and Buffeting Phenomena. Computational Wind Engineering (CWE 2006), Yokohama, Japan, 16-19 July 2006. 